ÉGYPTE monde arabe

\section{Égypte/Monde arabe}

$21 \mid 1995$

Économie égyptienne et perspectives de paix au

Proche-Orient

\title{
Économie égyptienne et perspectives de paix au Proche-Orient : introduction
}

\section{Louis Blin}

\section{OpenEdition}

\section{Journals}

Édition électronique

URL : https://journals.openedition.org/ema/365

DOI : 10.4000/ema.365

ISSN : 2090-7273

Éditeur

CEDEJ - Centre d'études et de documentation économiques juridiques et sociales

Édition imprimée

Date de publication : 31 mars 1995

Pagination : 7-10

ISSN : 1110-5097

Référence électronique

Louis Blin, «Économie égyptienne et perspectives de paix au Proche-Orient : introduction », Égypte/ Monde arabe [En ligne], 21 | 1995, mis en ligne le 08 juillet 2008, consulté le 07 juillet 2022. URL : http:// journals.openedition.org/ema/365; DOI : https://doi.org/10.4000/ema.365

Ce document a été généré automatiquement le 7 juillet 2022

Tous droits réservés 


\title{
Économie égyptienne et perspectives de paix au Proche- Orient : introduction
}

\author{
Louis Blin
}

1 Le dossier qui suit replace l'économie égyptienne dans son environnement régional, particulièrement dans les perspectives d'évolution économique que pourrait réserver le règlement du conflit israélo-arabe.

2 L'article introductif de Fathi Ibrahim analyse quelques caractéristiques économiques de l'Égypte des années 90, qui mettent en évidence ses atouts et handicaps dans la nouvelle compétition régionale qui se dessine. Loin du cliché pessimiste d'une économie foncièrement délabrée, l'auteur décèle des potentialités médiocrement exploitées: au niveau interne, les facteurs de production disponibles en Égypte l'appellent en théorie à un essor industriel remarquable; sur le plan externe, le stock de capitaux détenus à l'étranger par les nationaux dépasse largement le produit intérieur brut. Cependant, les réformes engagées depuis 1991 n'ont pas suffisamment fait évoluer les structures économiques pour que les Égyptiens soient incités à mettre leur patrimoine et leur travail au service du développement de leur pays, d'autres États profitant au contraire de leurs activités. Curieux paradoxe, ce sont plutôt des ressources de rente économique et géopolitique qui permettent aux Égyptiens de vivre - mieux que les statistiques ne le laissent penser - : il s'agit donc d'une richesse qui ne provient pas d'un travail autochtone. La dévalorisation stratégique d'un Proche-Orient pacifié et son ouverture économique pourraient y rétablir des logiques économiques qui feraient disparaître cette situation quelque peu "schizophrène ». Il apparaîtrait alors qu'une plus grande insertion de l'économie égyptienne dans le marché mondial favoriserait la mobilisation de ses capacités actuellement dispersées ou sousemployées, à laquelle aspiraient les politiques protectionnistes précédentes...

3 Constatant également que "l'attitude rentière continue de caractériser la politique économique égyptienne », Marie-France Vernier, dans l'article suivant, détaille le mode de captation par l'Égypte d'une partie de la rente pétrolière dont jouissent les pays du 
Golfe, principalement par le biais des remises des travailleurs égyptiens émigrés dans ces pays et des aides publiques que prodiguent ces derniers. Il souligne le contraste existant entre l'importance de ces transferts et la faiblesse du commerce égypto-arabe, et, au-delà, entre la densité des liens humains et le manque d'intégration économique $\mathrm{du}$ Moyen-Orient. La paix constitue probablement un facteur nécessaire, mais non suffisant, au renforcement de cette intégration.

Ce sont les conséquences que les flux économiques susceptibles d'être engendrés par la paix au Proche-Orient pourraient avoir sur les relations régionales de l'Égypte qu'analyse Jacques Seguin, dans une optique de géographie économique. L'auteur étudie l'impact potentiel des changements politiques sur la place de l'Égypte dans le système économique régional du Moyen-Orient, soulignant que son poids « lui confère une assurance contre les bouleversements", contrairement à d'autres pays de la région. Dans ces conditions, les nouvelles connexions que la fin du conflit israélo-arabe laissent entrevoir pourraient permettre au Sinaï de recouvrer sa vocation historique et géographique de relais pour les échanges, qui en fait un archétype de la fonction occupée par le Proche-Orient dans l'Histoire.

5 Sortant du cadre régional pour passer à l'étude des relations économiques entre le Moyen-Orient et l'Europe, Michel Galloux oppose leur importance à la faible intégration économique moyen-orientale, déjà mentionnée. L'apaisement quasisimultané des deux principaux conflits qui troublaient ces deux ensembles - guerre froide en Europe et conflit israélo-arabe au Moyen-Orient - facilitera-t-il leurs relations? Il apparaît pour le moment que les avantages qu'ils tireraient du développement d'un partenariat économique mutuel n'apparaissent pas assez décisifs aux décideurs européens pour qu'ils ne lui préfèrent un renforcement de l'intégration européenne, si bien que l'essor des relations économiques euro-arabes dans les années à venir pourrait largement dépendre de l'attitude des secteurs privés. Seule une libéralisation économique accélérée serait alors capable de vaincre les réticences des investisseurs européens, qui ont jusqu'à présent préféré d'autres contrées pour développer leurs activités internationales.

6 La prise en main de l'avenir économique par le secteur privé est-elle déjà engagée en Égypte ? L'analyse des élites économiques que présente Imco Brouwer tend à accréditer cette hypothèse. Leur place dans la prise de décisions économiques s'élargit en effet depuis le début de la décennie en cours, qui voit par ailleurs les hommes d'affaires s'affranchir du pouvoir politique. Simultanément, la composition sociale de la bourgeoisie d'affaires s'est diversifiée et de nombreux jeunes entrepreneurs sont apparus. Ceci rend plus complexe l'expression d'une communauté d'intérêts entre hommes d'affaires, davantage organisés en groupes de pression relativement disparates. Le secteur privé égyptien semble ainsi être une puissance en devenir, aussi bien dans ses relations avec le pouvoir qu'au niveau régional. Cependant, sa faible expérience des marchés étrangers lui fait encore craindre une libéralisation rapide des échanges, avec Israël notamment. L'utilisation de la dimension internationale pour parachever les succès locaux demeure encore l'exception, ce qui dénote la marginalité persistante de l'Égypte dans l'économie globalisée de notre temps. 


\section{AUTEUR}

LOUIS BLIN

CEDEJ 